ANUARIO DE Estudios MEDIEVALES

48/1, enero-junio de 2018, pp. 117-148

ISSN 0066-5061

https://doi.org/10.3989/aem.2018.48.1.04

\title{
LA JERARQUÍA POLÍTICA DE UN SISTEMA URBANO: EL BRAZO DE LAS UNIVERSIDADES EN LAS CORTES MEDIEVALES DE ARAGÓN*
}

\author{
THE POLITICAL HIERARCHY OF AN URBAN SYSTEM: \\ THE BRANCH OF THE CITIES IN THE MEDIEVAL ARAGONESE CORTS
}

\author{
GERMÁN NAVARRO ESPINACH \\ Universidad de Zaragoza \\ https://orcid.org/0000-0002-4225-2279
}

\begin{abstract}
Resumen: Las cortes y los parlamentos medievales fueron los escenarios principales de la acción política de ciudades y villas ante las monarquías y los estamentos privilegiados de las sociedades europeas de la Baja Edad Media. La colección de fuentes documentales Acta Curiarum Regni Aragonum permite analizar durante casi doscientos años (1336-1516) la jerarquía política que existía dentro del brazo de las universidades reales de Aragón. El orden de prelación que seguían los monarcas en las convocatorias, la preeminencia que concedían a las ciudades por delante de villas y comunidades de aldeas en los asientos en cortes o la propia conflictividad existente entre unas poblaciones y otras por mantener su rango superior son algunas de las noticias más interesantes que se han localizado en esta investigación. En última instancia, se estudia la función que ejercieron los procuradores municipales en cortes como agentes del estado, resaltando la nueva forma de hacer política que cuajó en el tránsito del siglo XIV al XV con la puesta en práctica de los ideales de derecho, justicia y bien común a través de la noción de representación.
\end{abstract}

Palabras clave: reino de Aragón; cortes; ciudades; jerarquía política; estado feudal; sistema urbano; baja Edad Media.

Abstract: Medieval corts and parliaments were the main stages for the political action of cities and towns versus monarchies and privileged estates in European societies in the Late Middle Ages. The collection of documentary sources Acta Curiarum Regni Aragonum enables us to analyse the political hierarchy within the branch of the Royal Cities of Aragon over a period of nearly two hundred years (1336-1516). The order of priority followed by the monarchs in the summons, the pre-eminence given to cities ahead of towns and village communities in seating arrangements in the Corts, and the conflict between some settlements and others to maintain their higher rank are some of the most interesting aspects that have been identified in this research. Finally, the role of municipal procuradores in the Corts as agents of the state is studied, highlighting the new way of undertaking politics that took shape in the transition from the $14^{\text {th }}$ to the $15^{\text {th }}$ century with the ideals of law, justice and common good through the notion of representation.

Keywords: Kingdom of Aragon; courts; cities; political hierarchy; feudal state; urban system; Late Middle Ages.

\section{SUMARIO}

1. Estados feudales tardíos y sistemas urbanos.- 2. El brazo real en las cortes de Pedro IV y Juan I (1336-1396).- 3. La nueva política en época de Martín I y el Interregno (1396-1412).- 4. Los agentes del estado con la dinastía Trastámara (1412-1516).5. Conclusiones.- 6. Bibliografía citada.

\footnotetext{
* Este trabajo ha sido realizado en el marco del proyecto TESTA "Las transformaciones del estado: estructuras políticas, agentes sociales y discursos de legitimación en el reino de Aragón (siglos XIV-XV)" con referencia HAR2015-68209-P del Ministerio de Economía y Competitividad del Gobierno de España. Además, el citado proyecto forma parte del programa de actividades del Grupo de Investigación de Referencia CEMA del Gobierno de Aragón en la Universidad de Zaragoza (H20_17R).

Cómo citar este artículo: Navarro Espinach, Germán (2018), La jerarquía política de un sistema urbano: el brazo de las universidades en las cortes medievales de Aragón, "Anuario de Estudios Medievales" 48/1, pp. 117-148. https://doi. org/10.3989/aem.2018.48.1.04

Copyright: (C) 2018 CSIC. Este es un artículo de acceso abierto distribuido bajo los términos de la licencia de uso y distribución Creative Commons Reconocimiento 4.0 Internacional (CC BY 4.0).
} 


\section{ESTADOS FEUDALES TARDÍOS Y SISTEMAS URBANOS ${ }^{1}$}

El coloquio internacional sobre competencias políticas e institucionales de las ciudades, celebrado en Madrid en 2015, nos permitió analizar en una de las ponencias el brazo de las universidades en las cortes medievales de Aragón ${ }^{2}$. Entre otras cuestiones se trataba de estudiar las ciudades en sus relaciones recíprocas de concurrencia, complementariedad, oposición, ayuda y colaboración continuada a partir del desarrollo y la capacidad política de sus gobiernos. ¿Hasta qué punto esa capacidad de acción de los poderes locales a través de sus procuradores en cortes consolidó la jerarquía simbólica del sistema de ciudades y villas del reino de Aragón que promovía la monarquía? Como es de imaginar, la respuesta requiere unas aclaraciones teóricas previas antes de entrar de lleno en materia documental puesto que, como decía Pierre Bourdieu cuando definió al estado como el "monopolio de la violencia física y simbólica legítimas", lo teórico solamente se entiende en conexión con lo empírico ${ }^{3}$. Por consiguiente, hablar de jerarquización política del sistema urbano nos conduce al debate sobre cuál fue el papel del estado dentro de las estructuras políticas de los siglos XIV-XVI y qué es lo que entendemos por "sistema urbano" en el contexto del feudalismo tardío imperante en Occidente durante de la Baja Edad Media y más allá.

Bourdieu quiso distanciarse un poco de la idea marxista clásica del estado como gestor de los intereses de las clases dominantes para intentar renovar el propio concepto. Sin embargo, tiene razón Chris Wickham cuando dice que, a pesar de que Marx no estuvo muy interesado en la Edad Media por considerarla un mundo precapitalista, el marxismo ha aportado el paradigma principal que tenemos hoy día sobre los elementos económicos fundamentales de aquella época. Y si bien sobre el estado bajomedieval no se ha teorizado tanto, la riqueza de las interpretaciones puestas en marcha en los últimos años augura un futuro positivo también en esta temática historiográfica, lo que quiere decir que el marxismo puede hacer mucho más en el futuro por la historia medieval ${ }^{4}$. El mismo Wickham ha defendido la existencia de hasta tres tipos de estado en la Alta Edad Media (400-800) que reproducen formas diferenciadas de centralización de la autoridad a través del ejercicio de la justicia y el desarrollo de ejércitos dentro de una noción común de poder público 5 .

\footnotetext{
${ }^{1}$ Abreviaturas utilizadas: ACRA = Acta Curiarum Regni Aragonum.

${ }^{2}$ Asenjo, Crouzet - Pavan 2015.

${ }^{3}$ Bourdieu 2014, p. 14.

${ }^{4}$ Wickham 2009, pp. 92-93.

${ }^{5}$ Wickham 2008, p. 115.
} 
El pleno desarrollo de los factores institucionales e ideológicos de ese tipo ideal de estado dependía en palabras de Wickham de que el poder de la clase gobernante contara con el suficiente respaldo económico, ya que únicamente la existencia de recursos estables hace posible un ejercicio permanente del poder. En verdad, según él, casi siempre ha sido posible distinguir a las clases dominantes de las instituciones del estado porque poseen una riqueza independiente aunque busquen perpetuarse también mediante la consecución de cargos oficiales en las jerarquías públicas ${ }^{6}$. Con todo, dicho autor reconoce que existen tantas definiciones de estado como autores dispuestos a teorizarlas pero lo importante es valorar cuáles resultan más o menos útiles cuando se confrontan con la realidad histórica ${ }^{7}$. Incluso, en su último libro traducido al castellano, Europa en la Edad Media. Una nueva interpretación, Wickham ha ampliado la cronología de su análisis más allá de la Alta Edad Media para adentrarse en la historia de los estados occidentales en el siglo XIII en adelante, haciendo hincapié en que la mayoría de los sistemas políticos europeos de la Baja Edad Media adquirieron una complejidad administrativa cada vez mayor ${ }^{8}$. Para dicho autor es especialmente interesante cómo el período 13501500 significó una verdadera "reconsideración de la política" en la Europa medieval, algo que atañe directamente a la temática que nos ocupa aquí. En ese sentido, frente a la fuerza de la política local que era hegemónica en todos los territorios, los estados feudales comenzaron a manifestar una creciente injerencia en los asuntos locales a través de la fiscalidad, las comunicaciones y el uso cada vez más intenso de la escritura. Y en medio de esta transformación importante uno de los elementos claves de cuantos legó el Medievo a las generaciones futuras fue, sin duda, la idea del compromiso político por el bien común como expresión repetitiva en numerosas acciones de gobierno9. Aportaciones destacadas en ese ámbito de análisis siguen insistiendo precisamente en las relaciones entre los reinos y las comunidades locales, destacando estrategias políticas basadas en el consenso y la representación que llegaron a ser utilizadas en época contemporánea para la construcción del mito de un Medievo constitucional ${ }^{10}$.

Sin embargo, el escenario de fondo, como ya planteó hace tiempo Paulino Iradiel, es un sistema político bajomedieval que se caracterizó por una pluralidad de cuerpos, grupos y centros políticos, más que el estado o los aparatos de estado, rompiendo así con ese esquema dualista del

\footnotetext{
${ }^{6}$ Ibidem, pp. 436-437.

${ }^{7}$ Ibidem, p. 1191 (dentro de la nota 2 del capítulo 3).

${ }^{8}$ Wickham 2017, p. 35.

${ }^{9}$ Ibidem, p. 388.

${ }^{10}$ Reynolds 1997; González 2007; Nieto 2007; Watts 2009; Hébert 2014; Genet 2017.
} 
estado frente a todo lo demás, y por tanto el análisis de la integración más o menos ventajosa de ese todo lo demás en el estado. En la práctica, las instituciones de Antiguo Régimen no expresaban un ordenamiento centrado sólo en el monarca ni reclaman sólo la atención del historiador sobre el «centro», esto es, los procesos de centralización o sobre temas como la burocracia, administración, eficacia y control de los aparatos de gobierno, entre otras cuestiones, sino también acerca de otras formas políticas complementarias del poder monárquico que también parte integrante del conjunto "corporado" del mismo: ciudades, señoríos, corporaciones, órdenes y grupos sociales ${ }^{11}$.

De todos modos, si queremos analizar fenómenos de jerarquización política habrá que reconocer que el estado es por excelencia la principal forma de división social del trabajo en tanto organización estructurada de la reproducción social. Su existencia puede entenderse como el desarrollo de un gran y singularizado proceso económico-social de desigualdad instituida entre la población a través de diversos mecanismos de segregación, dependencia y coerción que, a fin de cuentas, es lo que mejor define el poder del estado. Además, en el curso de los siglos XIII-XV se llevó a cabo un proceso global de transición del estado personal, concretado y fundado sobre la figura física del monarca -que no alcanzaba las otras realidades de su entorno más que a través de las relaciones personales y directas con sus súbditos- a otra idea de estado que reposará mucho más en la abstracción y en las estructuras no personales, donde la idea de poder público tiene más relevancia y donde la administración se interpone entre el rey y su pueblo. Se trata de la transformación gradual de las antiguas monarquías feudales surgidas a partir del siglo XI, las cuales se asociaron de modo progresivo con la concentración de poder, el desarrollo de medios más complejos de gobierno y la emergencia de una concepción abstracta de la utilidad pública o del bien común si se prefiere, fenómenos, todos ellos, acelerados, sin duda, por la misma crisis feudal de la Baja Edad Media. En ese sentido, cabe afirmar que la Corona de Aragón fue una monarquía centralizadora que presidió varios estados feudales entre la Península Ibérica (Aragón, Cataluña, Valencia) y el Mediterráneo (Mallorca, Sicilia, Cerdeña, Nápoles), cada uno de los cuales tuvo vida propia de manera evidente durante el siglo XV. Y, en efecto, la expansión de la escritura, el notariado y la burocracia jugaron un papel muy importante en la construcción de los estados feudales tardíos de la Corona de Aragón, entre ellos el reino aragonés ${ }^{12}$.

${ }^{11}$ Iradiel 1997, p. 84.

${ }^{12}$ Navarro 2004. 
Teniendo en cuenta esa percepción del sistema político bajomedieval como una pluralidad de cuerpos presididos todavía de forma limitada por el estado feudal tardío existe un último problema teórico que hay que tratar de resolver. Consiste en identificar las relaciones entre los diversos centros de población más importantes que había dentro de las fronteras del territorio de un estado dado, interpretar sus jerarquías y, sobre todo, las características del sistema urbano que constituyeron. Jerarquías en el sentido de reciprocidad entre los diversos centros capaces de influir de verdad en sus relaciones mutuas, en su número y más aún en sus funciones, en el grado de especialización de cada cual según sus actividades y servicios. Al respecto, entendemos como «sistemas urbanos» conjuntos relativamente organizados y orgánicos "quizás no necesariamente cohesionados desde el punto de vista territorial y geopolítico, pero igualmente capaces de condicionar mucho el modo de ser de las ciudades que formaban parte" ${ }^{13}$. Es aquí donde toma sentido el tema de las ciudades capitales de estado que hace un par de años ha sido tratado en un dossier especial de la revista Afers (núms. 80/81 del año 2015). El caso concreto de Zaragoza, capital medieval del reino de Aragón, pone en evidencia cómo la ciudad creció a medida que se estructuraba el estado feudal, erigiéndose en sede de las principales instituciones políticas y judiciales y en centro simbólico del poder del reino. De modo paralelo, las elites locales de la capital tomaron un protagonismo creciente frente a la monarquía que encarnaba al estado, sirviendo de modelo a imitar por parte del resto de ciudades y villas ${ }^{14}$. Y sin duda el terreno de juego donde mejor se observa esta jerarquización política del sistema urbano aragonés es el de las cortes y parlamentos cuyas actas nos van a permitir obtener noticias interesantes sobre cómo se gestó en cada reinado esta "reconsideración de la política" que Wickham considera fundamental como herencia que nos ha dejado la Edad Media.

En este artículo lo empírico es el conjunto de resultados obtenidos al estudiar los procesos de actas de las cortes medievales de Aragón que se están acabando de editar. Se trata de una serie de 16 tomos -algunos de ellos con dos y tres volúmenes- que constituyen la colección Acta Curiarum Regni Aragonum, dirigida por José Ángel Sesma y Carlos Laliena, con una cronología que abarca tres siglos de historia desde el reinado de Jaime I hasta el de Fernando II. Al día de hoy la edición está en fase final de ejecución, puesto que se han editado ya once tomos y los otros cinco restantes se encuentran en fase de publicación inminente, como sucede con el tomo 15 que está previsto

\footnotetext{
${ }^{13}$ Iradiel 1999, pp. 625-626 (nota 71).

${ }^{14}$ Laliena 2015. Sobre el sistema de ciudades y villas de Aragón en el siglo XV véase Navarro 2010 .
} 
que vea la luz este año o con el tomo 13 que aparecerá el próximo. Mientras tanto, los tomos 1, 12 y 14 siguen en fase de redacción e indización. En suma, los volúmenes de actas de cortes editadas sobre el que hemos trabajado aquí corresponden a los reinados de Pedro IV (1336-1387) y Juan I (1387-1396) ${ }^{15}$, Martín I (1396-1410) y el Interregno que terminó con el Compromiso de Caspe (1410-1412) $)^{16}$, Fernando I (1412-1416) ${ }^{17}$, Alfonso V (1416-1458) ${ }^{18}$ y Fernando II (1479-1516) ${ }^{19}$.

Entre 1336 y 1514 transcurrieron 178 años de historia con 48 reuniones de cortes y parlamentos de los aragoneses, nueve de ellas dentro de las Cortes Generales de la Corona de Aragón. La ciudad de Zaragoza fue 22 veces sede de las cortes particulares del reino ${ }^{20}$ y Monzón, por su ubicación estratégica en la frontera con Cataluña, lo fue en 8 ocasiones para las generales de la Corona $^{21}$. Así, pues, ambas localidades acapararon respectivamente las sedes donde se celebraron las reuniones frente al resto de lugares, una docena en total, que acogieron en menor medida las asambleas del reino: Alcañiz (1354, 1371-1372 , 1411-1412, 1436, 1441-1442), Daroca (1356), Cariñena (1357 y 1361), Barbastro (1362), Calatayud (1365-1366 y 1461), Caspe (1371-1372), Tamarite de Litera (1375 y 1383-1384), Fraga (1383-1384 y 1460), Maella (1404 y 1423), Teruel (1427-1428), Valderrobres (1429) y Tarazona (1484, 1495-1496 y 1502).

En las actas editadas, sin embargo, sólo se conservan 31 convocatorias incluyendo el Parlamento General celebrado en la localidad catalana de Gandesa en 1336. El orden de citación de las universidades que compusieron el brazo real constituye un primer indicador sobre la jerarquía simbólica existente entre ellas. La autoría de ese orden de prelación era responsabilidad del monarca y sus consejeros como también lo era el grado de prioridad establecido a la hora de tomar asiento en las sesiones, algo que de nuevo era un mandamiento emanado directamente del rey. En suma, orden de convocatoria y lugar de asiento son elementos importantes para nuestro análisis como se verá a continuación, estableciendo comparaciones mediante sendas tablas de datos primero para la época de Pedro IV y sus hijos Juan I y Martín I (13361410) y después para el período de gobierno de la dinastía Trastámara (1412-

${ }^{15}$ Sesma, Lafuente 2013; Laliena 2008; Sesma 2006, 2009.

${ }^{16}$ Navarro 2008 ; Sesma 2011a.

${ }^{17}$ Navarro 2009.

${ }^{18}$ Iranzo 2007; Laliena, Iranzo 2016; Tomás 2013b.

${ }^{19}$ Monterde 2011.

${ }^{20} 1336,1347,1348,1349,1350,1352,1360,1365-1366,1367,1371-1372,1381,1398-$ $1400,1411-1412,1412,1413-1414,1439,1441-1442,1442,1446-1450,1451-1454,1493-$ 1494 y 1498.

${ }^{21} 1362-1363,1375-1376,1383-1384,1388-1389,1435,1469-1470,1510$ у 1512-1514. 
1514). El transcurso de las sesiones y los cuadernos de agravios presentados por el brazo de las universidades permite profundizar en esas informaciones con algunas referencias interesantes sobre las aspiraciones y protestas que manifestaron algunas localidades sobre la alteración de la jerarquía política que desde antaño la monarquía estableció entre ellas.

\section{El BRAZO REAL EN LAS CORTES DE PEDRO IV Y JUAN I (1336-1396)}

Las actas de las cortes aragonesas más antiguas que se han editado al día de hoy corresponden a los primeros veinte años del reinado de Pedro IV y en ningún caso estamos hablando de procesos completos. En las Cortes de Zaragoza de 1336, convocadas para el juramento y coronación del rey, hubo 71 asistentes acreditados, de los cuales 23 asientos los ocupó el brazo real de las universidades, es decir, ciudades, villas y también aliorum locorum regni Aragonum. Por el brazo eclesiástico hubo 14 asistentes, 5 en persona y el resto mediante procuración. Del grupo nobiliar había hasta 20 representantes y los 13 asientos restantes correspondieron a caballeros e infanzones, el cuarto brazo característico de las cortes aragonesas a diferencia de otros países europeos. Sin embargo, el número de universidades o municipios cuyos jurados y prohombres fueron convocados fue de 22 y estuvo encabezado en primer lugar por las seis ciudades que había entonces en el reino con esa dignidad siguiendo este orden: Zaragoza, Huesca, Tarazona, Albarracín, Barbastro y Jaca. A continuación figuraban las villas más grandes de Calatayud, Daroca y Teruel con sus aldeas incluidas. Después fueron convocadas las villas de Ejea, Uncastillo, Borja, Tamarite de Litera, Aínsa, Pertusa y sus aldeas, Sariñena y sus aldeas, Zuera, Ariza y sus aldeas, Alcañiz y su tenencia, Montalbán, la villa de Alagón y Monzón ${ }^{22}$. La lista de municipios asistentes, sin embargo, mostraba matices interesantes. En primer lugar, no asistieron los procuradores de la ciudad de Albarracín pero sí los de las villas de Almudévar y Horta que no aparecían en la convocatoria original. Además, en algunos casos se citaban por separado los nombres de los procuradores de una villa y los nombres de los procuradores de sus aldeas, como sucede con Calatayud, Daroca o Sariñena, aunque las comunidades aldeanas no serán convocadas por separado como tales hasta $1354^{23}$.

${ }^{22}$ ACRA, tomo 2, p. 5.

${ }^{23}$ Ibidem, p. 8. 


\begin{tabular}{|c|c|c|c|c|c|c|c|c|c|c|c|c|c|c|c|c|c|c|c|}
\hline $\begin{array}{c}\text { VIaAW } \\
\text { NOIJISOd }\end{array}$ & $\begin{array}{l}\text { वे } \\
\text { త }\end{array}$ & $\left|\begin{array}{c}2 \\
\infty \\
\vdots \\
=\end{array}\right|$ & हे & $\begin{array}{l}8 \\
\pm \\
\end{array}$ & $\stackrel{?}{\stackrel{?}{ \pm}}$ & $\mid \begin{array}{l}2 \\
0 \\
n \\
n\end{array}$ & $\begin{array}{c}8 \\
8 \\
i\end{array}$ & 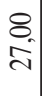 & $\begin{array}{l}2 \\
2 \\
2\end{array}$ & $\begin{array}{l}n \\
6 \\
i\end{array}$ & $\begin{array}{l}0 \\
n \\
= \\
-\end{array}$ & $\cong$ & $\underset{f}{\text { q }}$ & $\mid \begin{array}{l}\stackrel{8}{2} \\
\stackrel{7}{\sim}\end{array}$ & $\stackrel{2}{\sim}$ & $\stackrel{0}{\circ}$ & $\begin{array}{l}2 \\
2 \\
\pm \\
-1\end{array}$ & $\begin{array}{l}8 \\
\vec{i}\end{array}$ & $\stackrel{\overbrace{}}{\stackrel{\sim}{N}}$ \\
\hline $\begin{array}{l}\cdot \Lambda \mathrm{NOJ} \\
\mathrm{gd}_{\mathrm{o}} \mathrm{N}\end{array}$ & 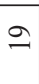 & = & 으 & - & శి & 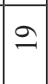 & - & -1 & $a$ & 이 & $\infty$ & $=$ & 으 & $\nabla$ & ㄱ. & 으 & ণి & + & $m$ \\
\hline ZItI-IItI & $\because$ & $\approx$ & $n$ & $\Xi$ & 으 & $\vec{\sim}$ & $\check{\sim}$ & & & 0 & & $r$ & $\simeq$ & & $\infty$ & 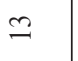 & $\approx$ & & \\
\hline t0tI & $\underline{2}$ & สี & $n$ & & 으 & $\vec{\sim}$ & & & & - & & 6 & $\infty$ & & $\infty$ & 2 & $\approx$ & & $\infty$ \\
\hline $00 t I-86 \varepsilon I$ & $\cong$ & ส & $n$ & & 으 & $\vec{\sim}$ & & & & $r$ & & o & $\infty$ & & $\infty$ & 9 & $\approx$ & & $\stackrel{\sim}{\infty}$ \\
\hline $68 \varepsilon I-88 \varepsilon I$ & ్ి & $=$ & $n$ & & 0 & $\simeq$ & & & & $m$ & & $a$ & $\approx$ & & $r$ & 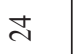 & $\approx$ & & \\
\hline 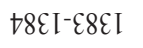 & $\approx$ & $\simeq$ & $n$ & & $=$ & 가 & & & & $m$ & & $a$ & 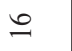 & & $r$ & 드 & $\vec{\sim}$ & & \\
\hline I8EI & $\infty$ & 0 & $\nabla$ & & 0 & a & & & & $a$ & & $\vec{\sim}$ & $\infty$ & & $\approx$ & 9 & $=$ & & \\
\hline $9 L \mathcal{E} I-\varsigma L E I$ & $=$ & $\vec{\sim}$ & $a$ & & $=$ & 士 & & & & 0 & & $\sim$ & $\approx$ & & $m$ & 鬲 & $\infty$ & & \\
\hline SLEI & $\simeq$ & $a$ & $\nabla$ & & $=$ & 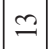 & & & ㄱ. & $r$ & & $\sim$ & & $\vec{\sim}$ & $m$ & & 드 & & \\
\hline ZLEI-ILEI & $\cong$ & శి & $\nabla$ & & $=$ & 士 & & & $\infty$ & 0 & & $r$ & & $\vec{\sim}$ & $\infty$ & & 으 & & \\
\hline L9EI & 으 & & & & $a$ & $\infty$ & & & & in & & $\sim$ & & & $m$ & & $\simeq$ & & \\
\hline $99 \varepsilon I-\varsigma 9 \varepsilon \mathrm{I}$ & $=$ & & & & $r$ & $=$ & & & & $m$ & & & & & in & & $\infty$ & & \\
\hline$\varsigma 9 \varepsilon I-† 9 \varepsilon I$ & 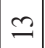 & & & & $\simeq$ & $\infty$ & & & & $m$ & & & & & in & & a & & \\
\hline 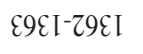 & શิ & $\approx$ & & & $\infty$ & $=$ & & & & $\sim$ & 二 & & & & - & & $\simeq$ & & \\
\hline 09E I & i & 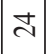 & & & $\approx$ & $\because$ & & & 2 & $\sim$ & $\approx$ & $\infty$ & $a$ & & o & r & 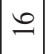 & & \\
\hline $9 S \mathcal{~ I}$ & $a$ & $\vec{\sim}$ & & & ㄱ. & $\because$ & & & $\approx$ & $n$ & $\stackrel{\sim}{\Delta}$ & $\infty$ & $\stackrel{\sim}{\sim}$ & & $r$ & ন & 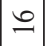 & స & \\
\hline$\downarrow \varsigma \mathcal{} I$ & & $\widetilde{\sim}$ & & & ৯े & 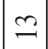 & & & $\hat{\sim}$ & $n$ & $\approx$ & $r$ & $a$ & $\infty$ & $\infty$ & 은 & $\simeq$ & $\theta$ & \\
\hline $8 t \varepsilon I$ & $\approx$ & $\approx$ & & & $\stackrel{\Delta}{\Delta}$ & $\cong$ & & 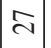 & 으 & $\nabla$ & \pm & 0 & & $\stackrel{\sim}{\infty}$ & - & & $a$ & 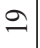 & \\
\hline$\angle t E I$ & $\approx$ & $\because$ & & & $\approx$ & 으 & & & $\approx$ & $n$ & \pm & $\infty$ & & & $n$ & & $=$ & 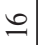 & \\
\hline $\begin{array}{c}\text { VSAGNVD } \\
9 \varepsilon \varepsilon I\end{array}$ & $\approx$ & ㄱ. & 0 & & $\infty$ & & & & ㅍ & $\nabla$ & $\simeq$ & $r$ & & & $\infty$ & & 으 & & \\
\hline \multirow[t]{2}{*}{ 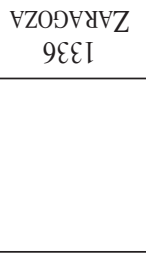 } & \pm & $\vec{\sim}$ & $\nabla$ & & $a$ & $\vec{\sim}$ & & & $\infty$ & in & $\simeq$ & $r$ & & & $\infty$ & & 이 & & \\
\hline & 旁 & 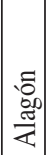 & 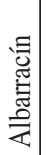 & 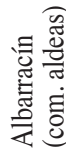 & 胥 & 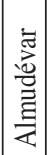 & 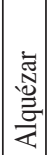 & 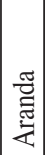 & $\cdot \stackrel{\mathbb{3}}{\mathbb{Z}}$ & 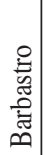 & 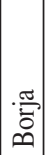 & 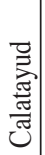 & 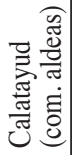 & שُ & 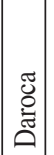 & 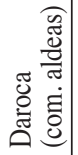 & 兽 & 풀 & 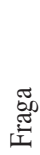 \\
\hline
\end{tabular}




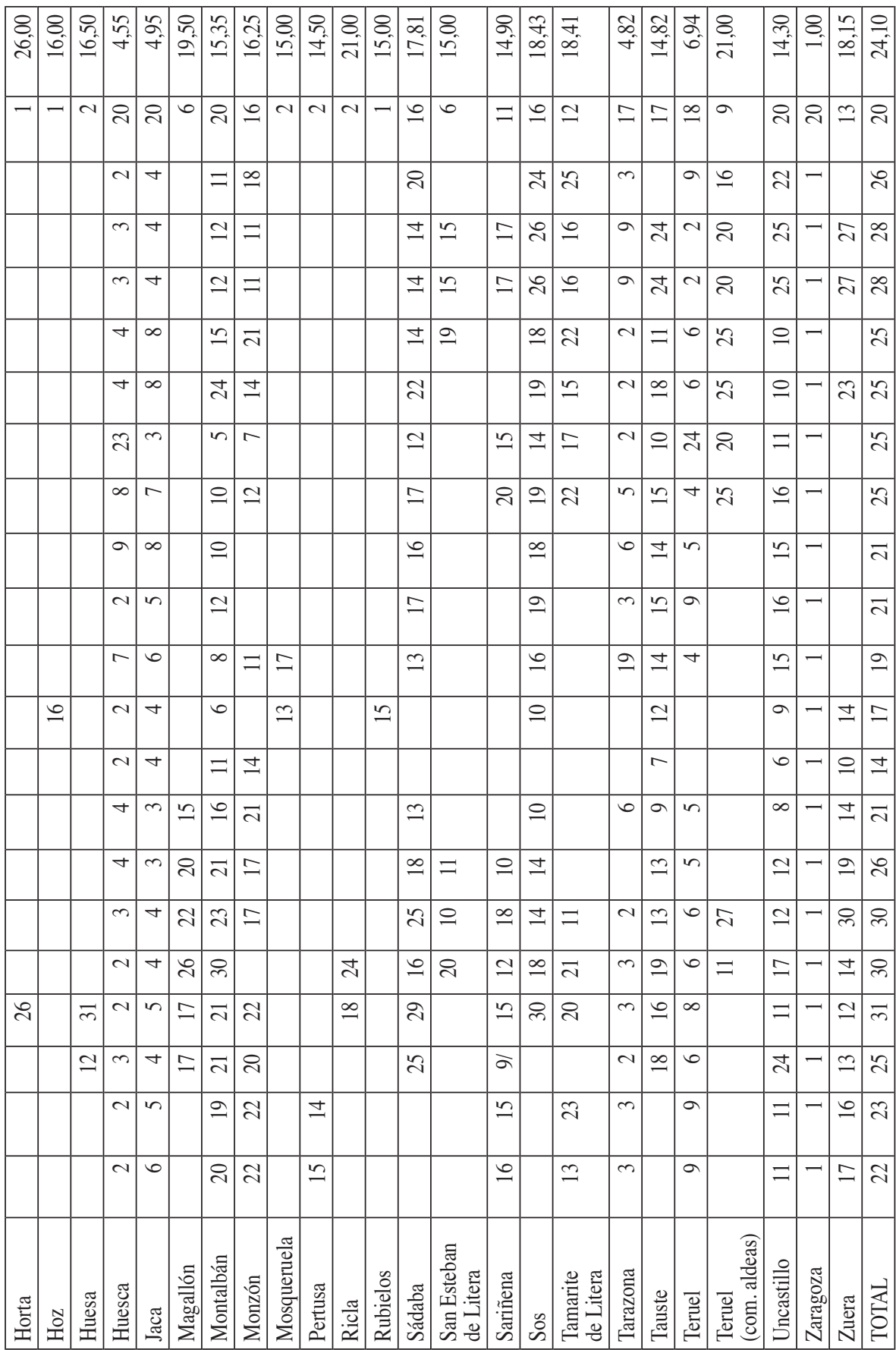


En la tabla 1 se recogen los 20 listados de convocatorias localizadas en las actas editadas asignando a cada población el número de orden con que aparecen citadas desde las Cortes de Zaragoza de 1336 hasta el Parlamento de Alcañiz y Zaragoza de 1411-1412, convocado en tiempos del Interregno por las elites políticas aragonesas en ausencia de soberano. La cifra de 43 entidades citadas sigue un orden alfabético para una mejor identificación. Las 20 convocatorias no tuvieron un número fijo de entidades entre otros motivos porque algunas pasaban a ser posesiones de señorío abandonando por ello el brazo real, de hecho oscilan entre las 14 citaciones de 1364-1365 y las 30 de 1354 o 1356 con una media de 24'10 universidades citadas por cada corte o parlamento de Aragón en los 76 años que transcurren desde el inicio del reinado de Pedro IV hasta el final del Interregno en 1412, que daría paso a la nueva dinastía de los Trastámara. La primacía de Zaragoza es indiscutible en las 20 convocatorias comparadas. Ser citada en todas ellas sólo lo comparte con Huesca, Jaca, Barbastro, Daroca, Ejea, Uncastillo, Alcañiz y Montalbán. En ese sentido, a excepción de la capital, la posición media de las ciudades del reino siempre era superior al octavo puesto en cualquier orden de convocatoria. De todos modos, en el Parlamento General de Gandesa de 1336 en comparación con las Cortes de Zaragoza anteriores del mismo año, sí que se incluía en su convocatoria a la villa de Almudévar y sus aldeas, aunque seguía sin estar Horta, cambiando el orden de las ciudades tras Zaragoza al colocar a Albarracín en último lugar: Civitatum Osce, Tirasone, Barbastri, Iacce et Albarrazini $^{24}$.

En la primera convocatoria de las Cortes de Zaragoza de 1347 se añadieron Magallón, Tauste y Sádaba a la lista de municipios y ya ni aparece Albarracín, como tampoco estará en las convocatorias posteriores que hubo para esta asamblea y en las que se incluyeron además Ricla, Épila, San Esteban de Litera, Horta y su tenencia, Aranda, Cetina, Sos y Huesa y sus aldeas ${ }^{25}$. Estas cortes de 1347 fueron aquellas en las que el rey otorgó el privilegio de ciudad a la villa de Teruel en agradecimiento al apoyo prestado durante la guerra de la Unión, reconociéndole así su particularidad foral ${ }^{26}$. En efecto, en la convocatoria de las Cortes de Zaragoza del año siguiente, 1348, ya figura entre las ciudades Civitatis Turolii et aldearum eius, sin que esté Albarracín tampoco. De igual modo, la villa de Huesa y sus aldeas, citada inicialmente,

\footnotetext{
${ }^{24}$ Ibidem, pp. 14-15. La diferencia entre Cortes y Parlamentos radica en que los segundos eran "las reuniones de todos o alguno de los brazos sin la necesaria presencia del monarca, pero siempre con su voluntad, para abordar alguna cuestión concreta que él proponía y que afectaba a los reunidos, sin la sujeción a las obligaciones y formalidades de las Cortes" como explican Sesma, Lafuente 2013, p. IV.

${ }^{25}$ Ibidem, pp. 28-29 y 32-33.

${ }^{26}$ Ibidem, pp. 38-39.
} 
quedó retirada de la lista por haberse convertido en villa de señorío y por consiguiente no proceder su convocatoria por el rey: Fuit data littera quod a modo non vocentur ad Curias cum dictus locus sit nobili Lupi de Luna. Sin Huesa el número variable de municipios que formaban el brazo de las universidades reales de Aragón llegó a alcanzar la treintena a mediados del siglo $\mathrm{XIV}^{27}$. Aunque en las Cortes de Zaragoza de 1352, tras los fueros otorgados en la asamblea anterior con ocasión de la crisis provocada por la Peste Negra, la cifra bajase de nuevo a 24 entidades convocadas ${ }^{28}$.

Fue por primera vez en el Parlamento de Alcañiz de 1354 cuando la convocatoria del brazo de las universidades separó explícitamente a las ciudades y villas de los comunes de sus aldeas ${ }^{29}$. Desde entonces el reconocimiento de las comunidades aldeanas de Teruel, Calatayud, Daroca o Albarracín a estar representadas en las Cortes de Aragón reforzaba todavía más si cabe el peso del estamento popular. El número de procuradores por cada población convocada variaba desde los dos o cuatro representantes habituales hasta los 17 delegados de la ciudad de Zaragoza, pasando por comunidades de aldeas con seis o siete procuradores a veces, multiplicando en suma la congregación de personas hasta casi el centenar y medio, el doble que hubo en las Cortes de Zaragoza de 1336. Además, en la sesión del 22 de abril de 1366 de las Cortes de Zaragoza y Calatayud de 1365-1366, las villas de Calatayud y Daroca recibieron el privilegio de llamarse ciudades en agradecimiento por los servicios prestados durante la guerra con Castilla. La expresión que se utilizó para mostrar la decisión del rey fue queriendo aquellos ennoblescer et gualardonar del buen servicio que feyto le havian en el caso de Calatayud, insistiendo después para Daroca que para la concesión de semejante título eran meritorios de haver nobleza et todo bien ${ }^{30}$. Y así en la convocatoria de las siguientes Cortes de Zaragoza de 1367 el listado de ciudades del brazo de las universidades era de siete en este orden: Zaragoza, Calatayud y sus aldeas, Daroca y sus aldeas, Teruel y sus aldeas, Barbastro, Jaca y Huesca ${ }^{31}$.

La ausencia de un municipio por no haber sido convocado a cortes por el rey no era obstáculo sin embargo para presentarse en la asamblea con sus procuradores y reclamar sus derechos. Es el caso de Albarracín y sus aldeas, cuyos representantes explicaron en la sesión del 18 de marzo de 1367 lo siguiente:

\footnotetext{
${ }^{27}$ Ibidem, pp. 122-123.

${ }^{28}$ Ibidem, p. 162.

${ }^{29}$ Ibidem, p. 172.

${ }^{30}$ ACRA, tomo 3, p. 87. Sobre el rango de ciudad frente a villas y aldeas en Aragón véase Navarro 2010.

${ }^{31}$ Ibidem, p. 105.
} 
que la ciudat de Albarrazin en todo tiempo fue llamada a las Cortes de Aragon entro agora que en el mes de mayo del anyo primero pasado non fue llamada la dita ciudat de Albarrazin. Et como antiga de tanto de razon et costumbre antiga deviera seer llamada ni encara a estas Cortes de present en las quales ditas Cortes de Calatayu por las quantias al dito senyor rey ally mandadas, las quales echaron conpartimiento por fogages por los trasoreros de los nobles et de las universidades, salva la excellencia del dito senyor rey et de las ditas Cortes, honor et reverencia de los sobreditos, muyt injustament la dita ciudat de Albarrazin et el Comun de las aldeas de aquella fue comdempnada en absencia en cierta quantia a pagar por los ditos fogages ${ }^{32}$.

La discordia interna del brazo de las universidades por el reparto de cargas en función del número de fuegos de cada población era habitual y siempre se le requería tiempo al monarca para poder reunirse por separado y acordar una distribución lo más equilibrada posible. Algunas poblaciones de frontera aducían por ejemplo que debían cargar con el mantenimiento de castillos que dependían de ellas como Calatayud por ejemplo, cuyos procuradores insistían en que ellos sostienen et pagan la retenencia de VII castiellos por sguart et carga de la qual les fue otorgado por el senyor rey que non pagarian $^{33}$. Queda claro también que la asistencia regular de los delegados municipales a las sesiones de las cortes era en la práctica bastante reducida, salvo en las sesiones más solemnes o cuando se negociaban temas de importancia. Especial atención merece el Quadernio de los greuges et supplicaciones dados et offrecidos por el braço de las universidades reales del regno de Aragon et por algunos singulares de aquell, incluido en las actas del proceso de las Cortes de Caspe, Alcañiz y Zaragoza de 1371-1372. Estamos ante el primer texto de estas características que se conserva, registrando un total de 123 agravios.

Por ejemplo, Horta y sus aldeas o el lugar de Fuentes reclamaban su presencia en cortes porque siempre habían formado parte de la junta de Zaragoza dentro de los límites del reino de Aragón, siendo tirados et removidos aquellos de la dita junta y no vueltos a convocar jamás. En otros casos como Ejea, Sádaba o la Vall d'Aran habían dejado de ser citados por el brazo de las universidades porque algunos de sus vecinos lo eran por el brazo de los caballeros e infanzones y por lo tanto reclamaban su presencia en calidad de municipios $^{34}$. La pertenencia a un brazo u otro convertía en irregular pues la composición del estamento popular a lo largo del tiempo, algo que como se

\footnotetext{
${ }^{32}$ Ibidem, p. 127.

${ }^{33}$ Ibidem, p. 150.

${ }^{34}$ Ibidem, pp. 448-502. Los ejemplos citados en p. 449.
} 
ve no sólo se debía a la conversión de una población en señorío. Al respecto, las villas de Alcañiz y Montalbán habían sido desde principios del reinado de Pedro IV integrantes del brazo de las universidades pero en el citado cuaderno de agravios denunciaban que sus comendadores a través del brazo eclesiástico habían logrado excluirlas de un tiempo a esa parte por detentar el carácter de señoríos de órdenes militares ${ }^{35}$. Algo parecido sucederá años más tarde a la villa de Fraga y sus aldeas en la frontera con el principado de Cataluña que, a pesar de estar pobladas a fuero de Aragón y usar moneda jaquesa, Pedro IV no las había convocado a las Cortes de Tamarite de $1375^{36}$.

Hay una queja en las Cortes de 1371-1372 que tiene mucha relevancia por lo que significa para el tema de la jerarquización política de las principales poblaciones del reino de Aragón. La presentaron los procuradores de Teruel y sus aldeas 24 años después de recibir el privilegio de ciudad, condición que le otorgaba entre sus nuevas prerrogativas lo siguiente:

Et en la tractacion de aquello gano Teruel el honor en muytos casos, de los quales es la uno que ensediendo o logar e en favllando en Cortes generales o en otros actos et aplegamientos comunes del regno, deve estar et haver voz luego en consequencia o apres el lugar o sedes et vozes et dezir de los lugares primero contos en ciudades que son notorios, a saber, es entre los otros Caragoça, Huessqua, Jacca, Taraçona, et assi lo obtuvieron en otras Cortes generales, segunt esto se sabe bien el Justicia de Aragon et otros et debe seer scripto en registros de don Miguel de Villanueva o de Johan Cavero, notarios qui fueron de las Cortes pasadas en el dito tiempo, et esta en memoria del dito Justicia et de otros. Et como agora la dita real magestat, con su reverencia favlando, tocando los ditos suplicantes en el dito dreyto et honor por aventura, por oblidanza o inadvertencia o por inportunidat, los haya pospuestos en la dita sedilla et voz non tan solament a Calatayun et Darocha, despues creadas en ciudat, mas a los de Alcannyz et de Montalvan, que son villas, a las quales eran postpuestas en tiempo que Teruel era villa, assi honrada como qualquiere villa del regno et de gran part del regno en todos actos, et de hombres de cavallo et de pie de si et de sus aldeas qui goyan se deven del dreyto, honor et libertat de su çiudat iuxta illud vicci enim iure gaudet inclite urbis, demandan por esto et suplican a la dita real magestat, con toda reverencia, qu'el dito prejudicio et innovamiento tirando, sian tornados alla dita honor, dreyto et possession en los quales eran et devian estar en las Cortes pasadas et aun en las presentes ${ }^{37}$.

\footnotetext{
${ }^{35}$ Ibidem, p. 463.

${ }^{36}$ ACRA, tomo 5, p. 29.

${ }^{37}$ ACRA, tomo 3, pp. 489-490.
} 
A tenor de lo dicho, el privilegio real que otorgaba la condición de ciudad a una población incluía el honor de sentarse y tomar la palabra en las sesiones de cortes por delante de las villas del reino y sólo por detrás de las otras ciudades más antiguas. Sin embargo, los de Teruel y sus aldeas habían visto como se incumplía en su caso esta jerarquía simbólica. En la convocatoria de las siguientes Cortes de Tamarite de Litera de 1375 el orden de citación establecido por el monarca no se hizo eco de la protesta de los de Teruel, pero sí de la de los de Albarracín que no figuraban con sus aldeas ${ }^{38}$. Por añadidura, las actas del proceso de las Cortes Generales de Monzón de 13751376 nos permiten obtener una comparativa general con los otros estados de la Corona de Aragón. La lista de convocados era en conjunto de unos 270 según un padrón de que disponía la cancillería real y que incluía las siguientes cifras por reinos ${ }^{39}$ :

- 135 representantes catalanes de los que asistieron sólo 21 en total (un $15 \%$ ): 44 de la Iglesia, 68 de los nobles y de la milicia y 23 universidades.

- 70 representantes aragoneses de los que asistieron sólo 40 (un 60 $\%$ ): 20 del brazo eclesiástico, 35 del brazo de los nobles y milites y 25 por el de las universidades.

- 63 representantes valencianos de los que asistieron 16 (un $25 \%$ ): 11 eclesiásticos, 40 del grupo militar y 12 representantes de las ciudades y villas.

Con todo, lo más interesante del proceso es que permite conocer por vez primera el modo en que debían sentarse todos ellos en la corte por orden del mismísimo rey: Modus autem sedendi coram dominus rege in dicta Curia generali predictis de ipsa Curia per eundem dominum regem ordinatus ut predicitur est hic. El esquema plasmado en la sesión del 23 de marzo de 1376 constituye un primer retrato simbólico de la jerarquización política de los estados peninsulares de la Corona de Aragón por estamentos. El rey destacaba en su trono en el centro del escenario con sus consejeros delante y siempre por debajo de él. Los prelados, ricoshombres y caballeros de los reinos de Aragón y Valencia estaban sentados en las gradas de su derecha y los de Cataluña en las de la izquierda. En las bancadas del medio, enfrente del soberano, el brazo real de las universidades debía cumplir el siguiente orden de preeminencia ${ }^{40}$ :

${ }^{38}$ Ibidem, p. 507.

${ }^{39}$ Sesma 2006, p. VI.

${ }^{40}$ ACRA, tomo 4, p. 37. 


\begin{tabular}{|l|l|l|l|}
\hline València & Zaragoza & Barcelona & Lleida \\
\hline Xàtiva & Huesca & Girona & Perpinyà \\
\hline Morella & Tarazona & & \\
\hline Alzira & Calatayud & & \\
\hline & Daroca & & \\
\hline & Barbastro & & \\
\hline & Teruel & & \\
\hline
\end{tabular}

Las Cortes Generales de Monzón, Tamarite de Litera y Fraga de 1383-1384 también reproducen la jerarquía política del sistema urbano de los reinos hispánicos de la Corona de Aragón entrando a mayor detalle en la descripción al aludir a la disposición de los escaños en el salón principal del castillo de Monzón en la sesión del 12 de junio de 1383:

in ipsa curia aragonensis et valentini ad dexteram et catalani et maioricensis ad sinistram sui regii solii, videlicet quod in utroque latere ponerentur in longum versus ipsum regium solium tria scanna, in quorum primo versus parietem utriusque lateris palacii castri Montissoni ubi alias talia facta affuere prelati et persone ecclesiastice, et in inmediate sequenti barones et nobiles et ipsorum procuratores, et in sequenti milites et persone militares consederent, ita quod in parte sinistra sedentes facies contra seu versus in leva sedentes et econverso tenerent, et quod ante ipsum tronum regium ponerentur in transverso plura scanna in parte utraque sic quod per medium dicti palacii liber transitus inter scanna eadem a portali palacii pretacti usque ad solium regium haberetur, in quibus siquidem scannis sindici civitatum et villarum sederent, quilibet in parte provincie sue, prout de prelatis, baronibus, nobilibus et militibus superius est distinctum, facies suas versus solium regium continentes ${ }^{41}$.

A diferencia de aquella sesión de 1376 comentada con anterioridad, ahora en la de 1383 aparecen en la izquierda del trono los catalanes acompañados de los mallorquines, haciendo constar que se sentaban en los escaños del brazo real los síndicos de ciudades y villas, cada cual en la parte correspondiente a su provincia, según un grado de prioridad que se reiterará en la sesión del 13 de noviembre de 1388 dentro de las Cortes Generales de Monzón de 1388-1389, las únicas que se celebraron en el reinado de Juan I, sucesor de su padre Pedro IV, fallecido en 1387. Sólo se ha detectado una diferencia entre ambas listas de 1383 y 1388 y es que en la segunda aparece la población catalana de Berga detrás de Vilafranca del Penedès y delante de Cotlliure ${ }^{42}$ :

${ }^{41}$ Ibidem, p. 189.

${ }^{42}$ Ibidem, pp. 190 y 296 


\begin{tabular}{|l|l|l|l|}
\hline Zaragoza & Valencia & Barcelona & Mallorca \\
\hline Huesca & Xàtiva & Lleida & Girona \\
\hline Tarazona & Morella & Perpinyà & Tortosa \\
\hline Calatayud & Morvedre & Manresa & Vic \\
\hline Daroca & Alzira & Cervera & Montblanc \\
\hline Teruel & Orihuela & Puigcerdà & Vilafranca del Penedès \\
\hline Albarracín & Burriana & $\begin{array}{l}\text { Vilafranca de } \\
\text { Conflent }\end{array}$ & Cotlliure \\
\hline Jaca & Castelló de Burriana & Figueres & Cambrils \\
\hline Barbastro & Alacant & Serbós & Torroella de Montgrí \\
\hline Alcañiz & Vila-real & & \\
\hline Montalbán & Vila del Pont & & \\
\hline Monzón & Castelfabib & & \\
\hline Aínsa & Ademuz & & \\
\hline $\begin{array}{l}\text { Tamarite de } \\
\text { Litera }\end{array}$ & & & \\
\hline Tauste & & & \\
\hline Ejea & & & \\
\hline Sariñena & & & \\
\hline Sos & & & \\
\hline Sádaba & & & \\
\hline Uncastillo & & & \\
\hline
\end{tabular}

Son 20 ciudades y villas aragonesas, 17 catalanas, 13 valencianas y Mallorca. El largo reinado de Pedro IV y el de su hijo Juan I habían concluido tras una actividad parlamentaria trepidante que había consolidado sin duda la fuerza del brazo de las universidades reales de la Corona y les había dotado ya de una jerarquía simbólica repetitiva que seguiría reiterándose en el futuro. Numéricamente alcanzaban como mínimo la mitad de las personas asistentes. El listado unificado de todas las cortes celebradas en los distintos reinos muestra un estado de permanentes reuniones entre el soberano y los estamentos concentradas en una treintena de años. Así, pues, el período 1356-1389 visto desde la perspectiva de las cortes particulares de Aragón, Cataluña y Valencia junto a las generales de la Corona dibuja un cuadro de una actividad tan intensa que no tenía precedentes ni volvería a repetirse en la historia parlamentaria de los países de la Corona de Aragón ${ }^{43}$.

${ }^{43}$ Sesma (ed.) 2009, p. V. 


\section{LA NUEVA POLÍTICA EN ÉPOCA DE MARTÍN I Y EL INTERREGNO} (1396-1412)

La "reconsideración de la política" que decía Wickham se hace latente con claridad en Aragón tras la muerte repentina del rey Juan I en mayo de 1396, aunque ya debía venir de antes. Lo cierto es que desde el óbito del monarca hasta septiembre de 1397 los cuatro brazos de las cortes aragonesas decidieron reunirse por cuenta propia en ausencia de soberano y de manera urgente en Zaragoza para garantizar la defensa del reino frente a las tropas del conde de Foix, casado con la única hija del difunto monarca, que reclamaba para si el derecho al trono. Se trataba de comprometer al hermano y sucesor de Juan I, el rey Martín I, para que acudiese a la capital aragonesa para prestar juramento y atender los problemas que le planteasen. A esta "congregación o parlamento" de los brazos del reino de Aragón asistieron 5 representantes del brazo eclesiástico, 10 nobles, 17 caballeros e infanzones, 8 procuradores de la ciudad de Zaragoza y un número indeterminado de representantes de las universidades del brazo real ${ }^{44}$. Por fin, tras un largo viaje desde que partiera de Sicilia, el rey Martín hizo su entrada en Zaragoza el 7 de octubre de 1397 y hasta el 6 de marzo del año siguiente no efectuó la convocatoria de las que serían las Cortes de Zaragoza de 1398-1400, dirigida a 83 titulares de los cuatro brazos, es decir, 19 eclesiásticos, 14 nobles, 23 caballeros y 28 universidades. En la sesión de apertura del 29 de abril asistieron 73 personas (14 eclesiásticos, 12 nobles, 17 caballeros y 30 síndicos de 11 universidades). Tras diversas adhesiones posteriores a la convocatoria a lo largo de los dos años de duración de estas cortes, la solemne sesión de clausura del 4 de abril de 1400 contó con la asistencia de hasta 105 personas: 12 eclesiásticos, 14 nobles, 50 caballeros y escuderos, y 29 procuradores de 13 universidades. El cuaderno de agravios inserto en el proceso de estas cortes registra un total de 203 documentos, de los cuales más de la mitad (123 en concreto) pertenecían al brazo de las universidades ${ }^{45}$.

Cuatro años después de sus primeras cortes aragonesas, el rey Martín I puso en marcha otras el 30 de mayo de 1404 en Maella, aumentando a 127 el número de convocados: 21 eclesiásticos, 21 nobles, 57 infanzones y 28 universidades. La sesión de apertura fue en el castillo de dicha población pero antes de comenzar el discurso inaugural el monarca observó la estrechez del sitio y la imposibilidad de colocar bien hasta su propio trono en relación con los asientos de los 54 asistentes (9 de la Iglesia, 6 de los nobles, 19 caballeros

\footnotetext{
${ }^{44}$ Navarro (ed.) 2008, pp. III-IX.

${ }^{45}$ Ibidem, pp. XIII-XIV, XVIII y XX.
} 
y 20 síndicos de 9 universidades), todos ellos sentados segunt sus grados et orden devido como se indica en el proceso, de modo que decidieron trasladarse a la iglesia de San Esteban, que era la iglesia mayor de la villa ${ }^{46}$. El principal resultado de esta asamblea que duró sólo unos días (del 26 de julio al 1 de agosto) fue la imposición de un fogaje general para mitigar las deudas y censales que tenía el reino. La recaudación se produjo en 1405 y supuso un retrato claro del peso demográfico que tenía cada brazo de las cortes con vistas al sostenimiento de la hacienda pública. Estamos hablando de un conjunto de 42.227 casas repartidas entre 600 núcleos de población: 20.357 del brazo de las universidades (48 \%), 10.379 del brazo de la iglesia (25\%), 7.417 del brazo de la nobleza $(18 \%)$ y 4.074 del brazo de los infanzones $(9 \%)^{47}$.

Las actas de las cortes de Martín I muestran por primera vez copia detallada y exhaustiva de todas las reuniones que efectuaron los concejos para nombrar a los procuradores que les iban a representar. Lo más importante es que se inserta en estos documentos la nómina de asistentes a las reuniones municipales que los designaron permitiendo crear una base de datos prosopográfica de enorme interés para la historia de muchas localidades que no conservan actas de sus concejos en fechas tan tempranas, como por ejemplo la mismísima Zaragoza. Se estaba iniciando un nuevo tiempo histórico para el brazo real de las cortes aragonesas que encontraría el punto álgido de su fuerza política tras la muerte de Martín I sin heredero legítimo el 31 de mayo de 1410. La misma cultura política que puso en marcha a los brazos del reino tras la muerte de Juan I en 1396 volvía a inspirar la reunión de nuevas congregaciones o parlamentos a la muerte de Martín I en los tres estados peninsulares de la Corona: Aragón, Cataluña y Valencia. Se sancionaba así la aplicación de la razón, la justicia y los derechos poseídos como única vía válida y legítima frente al argumento de la fuerza y de la violencia que quisieran promover los candidatos al trono. Derechos y justicia, como dice Sesma, serían las palabras claves en una arquitectura del pensamiento político que se repite en los discursos y debates de los tres parlamentos y que se ampara sobre la noción de representación:

La existencia, por tanto, de un poder institucional coordinado impidió, durante los primeros momentos del interregno, la proclamación por la fuerza de alguno de los candidatos y favoreció que se impusiese el criterio de abordar la sucesión por la vía de la justicia y esperar a la designación del que presentara mayores derechos ${ }^{48}$.

\footnotetext{
${ }^{46}$ Ibidem, pp. XXV-XXVI.

${ }^{47}$ Ibidem, pp. XXXII-XXXIII.

${ }^{48}$ Sesma (ed.) 2011,p. XI.
} 
El jurista Berenguer de Bardají, Gil Ruiz de Lihori, gobernador del reino, Domingo Ram, obispo de Huesca, y Juan Jiménez Cerdán, justicia de Aragón, se constituyeron en los coordinadores efectivos del Parlamento de Alcañiz-Zaragoza de 1411-1412 del que surgió la Concordia de Alcañiz firmada por los parlamentos de Aragón y Cataluña el 15 de febrero de 1412. Dicha concordia posibilitó las reuniones de los nueve representantes (tres por cada uno de los tres estados), clasificados también en tres grados por sus respectivas provincias de origen. Ellos deliberaron en los meses siguientes qué candidato poseía más derechos para la sucesión, emitiendo la sentencia final del Compromiso de Caspe el 25 de junio, hecha pública tres días después $^{49}$. En este punto, el interés de los municipios del reino por conseguir la vuelta a la normalidad en la cúspide del estado feudal tardío que encarnaba la monarquía queda latente por la cuantiosa representación de procuradores que asistieron al Parlamento de 1411-1412 en nombre de Zaragoza y del resto de ciudades, villas y comunidades de aldeas. Las cifras de asistencia comparando unos brazos con otros son contundentes. Asistió un $60 \%$ de los convocados por el brazo eclesiástico, menos del $40 \%$ de la nobleza y un $25 \%$ de los caballeros. Mientras tanto, el porcentaje de asistencia fue alto y constante en el brazo real (18 universidades de las 26 convocadas, un $69 \%$ ), lo que quiere decir que en la treintena habitual de participantes en las sesiones parlamentarias la mayoría que tomó las decisiones la conformaban juristas que representaban al brazo real a la par que el alto clero y sus procuradores $^{50}$.

En las actas del Parlamento de Alcañiz-Zaragoza de 1411-1412 se observa incluso la preocupación de los síndicos de algunos concejos como Huesca, Sos, Fraga o San Esteban de Litera por no poder asistir a las sesiones debido a la inseguridad y a los actos de violencia que acontecían en las tierras del norte desde las que debían trasladarse con gran dificultad. En la sesión del parlamento del 15 de septiembre de 1411 se presentó una misiva de los jurados de Huesca en la que informaban de los contactos que establecieron con los de Barbastro y Jaca para conformar una comitiva en el viaje, considerados los inconvenientes, periglos et scandallos que son et se cometen cada dia por los caminos en diversas partes de aqueste regno ${ }^{51}$. El 16 de octubre siguiente el propio parlamento contestaba a los jurados de Huesca dándoles instrucciones claras de cómo debían nombrar a sus procuradores según era costumbre:

${ }^{49}$ Sesma, Laliena, Monterde 2012.

${ }^{50}$ Sesma (ed.) 2011,pp. XXXII-XXXIII.

${ }^{51}$ ACRA, tomo 7, vol. 1, p. 61. 
Et primerament, bien sabedes o podedes saber que si Cortes o Parlament general d'Aragon se han de ajustar, la procuracion de poder que ha a fazer cada una universitat de aquest regno por intervenir en Cort o Parlament de aquell ha star dictada en cierta forma por fuero et costumbre del regno introduzida. Et, entre otras cosas, ha a aver clausula que se de poder al procurador pora fer et firmar todas et cada unas cosas que en la dita Cort o Parlament seran tractadas, ordenadas, acordadas, stablidas et firmadas. Et como, segunt el tenor de vuestra letra, la procuracion e poder por vosotros offrecida et dada a vuestros procuradores misatgeros por intervenir en el Parliament d'Aragon sia feyta en la dita forma antes en otra forma en la manera por nosotros limitada et restrenyida muyt perjudicial al regno d'Aragon e encara aquexa ciudat, por tanto los procuradores por vosotros en la dita forma limitada ordenados son scusados de no acebtar la procuracion, et finqua del todo la carga a vosotros et a los subjunges de la ordinacion que entre vosotros fue feyta; tal ordinacion qui sabedes que disponer et ordenar en tal articlo no pertenece a vosotros particularment, mas solament a la universidat del regno ${ }^{52}$.

Lo cierto es que la organización político-institucional del reino de Aragón permitió la gobernación del mismo durante el año y medio que duró el Interregno sin que la sociedad apenas notara la ausencia de rey. Pero, ¿por qué se produjo esa reconsideración de la política en este momento histórico y no en otro en la Corona de Aragón? Tal vez porque la quiebra de la línea natural de sucesión aconteció en una coyuntura muy predispuesta para hacerlo:

La monarquía era imprescindible, pero la idea de gobierno y la forma de ejercerlo y participar en él estaban cambiando. Parece un hecho constatable que desde hacía unos decenios había irrumpido en el ámbito superior de la sociedad una nueva elite política, desvinculada de la clase noble tradicional y su concepción del poder, que desde las instituciones representativas de los reinos (Cortes, Diputaciones del General, Justicia de Aragón), los gobiernos municipales, los funcionarios reales aportados por la baja nobleza urbana (gobernadores, bailes, merinos) y las jerarquías eclesiásticas (arzobispos, obispos, maestres y abades), tenía capacidad para desplegar un poder alternativo al desarrollado durante siglos por la nobleza y hacerlo, además, con argumentos morales y de defensa del bien común muy distintos a los personales y coercitivos habituales de los grupos militares. La sociedad civil había penetrado ya en la organización del Estado y las relaciones entre el rey y los representantes de los reinos se manifestaban además a través de conductos más abiertos y generales, y no solo de los señores naturales ${ }^{53}$.

${ }^{52}$ Ibidem, p. 104.

${ }^{53}$ Sesma 2011,p. 10. Véase también Sesma, Laliena 2012. 


\section{LOS AGENTES DEL ESTAdO CON LA DiNASTÍA TRASTÁMARA (1412-1516)}

Hay que centrar la atención, pues, en el estudio de aquellas personas o colectivos sociales que ejercieron funciones propias del poder público, tanto desde dentro como desde fuera de las instituciones, manteniendo un vínculo directo con la monarquía mediante actividad política a escala supralocal, tal y como proponía el reciente coloquio organizado por el Grupo CEMA y el Proyecto TESTA en la Universidad de Zaragoza los días 20-21 de junio de 2017 bajo el título Los agentes del Estado. Poderes públicos y dominación social en Aragón (siglos XIV-XVI). Si tuviéramos que poner algún ejemplo significativo de esos pioneros en las nuevas formas de hacer política en Aragón hablaríamos sin duda del ya citado Berenguer de Bardají, fallecido en 1433 y originario de Ribagorza. Un hombre de leyes que en las Cortes de Maella de 1404 fue uno de los ocho diputados elegidos para recaudar el fogaje general del reino. Como jurista estaba al servicio del rey Martín I en calidad de consejero y regente de la cancillería. Durante el Interregno fue una de las figuras claves del Parlamento de 1411-1412 junto al gobernador del reino y el justicia, de hecho, se le considera artífice directo de la Concordia de Alcañiz, participando además en el Compromiso de Caspe como uno de los apoyos principales que tuvo Fernando de Trástamara para ser considerado el candidato con más derechos para el trono de Aragón. Y así se lo agradeció en su testamento ${ }^{54}$. Al respecto, cuenta una crónica incompleta del nuevo monarca que también le aconsejó al soberano en la cumbre de Perpiñán de 1415 que se sustrajera de la obediencia del papa Luna con la opinión favorable en ese mismo sentido de los teólogos Vicente Ferrer y Felipe de Malla. Lo reconoce la crónica de Vagad cuando dice que en Perpiñán mostráronse los famosos letrados y sobre todos y más que todos el excelente y aventajado doctor mossén Beringuel de Bardaxín, con quien todos estaban de acuerdo, hasta el punto de que el emperador le requirió y rogó a la postre que se fuesse con él en Alemaña ${ }^{55}$.

Si ponemos la mirada sobre los procuradores del brazo real localizaremos a otros personajes que luego ocuparon cargos importantes en el entorno de los monarcas. Es el caso de Juan Ruiz, jurista de Daroca que representó a su ciudad en las Cortes Generales de Monzón de 1435-1436 y en las Cortes de Alcañiz de 1436, a la vez que trabajaba como abogado de la comunidad de aldeas de Daroca en otros asuntos. En las Cortes de Alcañiz de 1441-1442 figura ya como consejero real y en 1443 el rey Alfonso $\mathrm{V}$ le nombró merino de la ciudad de Zaragoza. La estancia del jurista Juan

54 Tomás 2013.

${ }^{55}$ Navarro 2015a. 
Ruiz en la corte de Nápoles está también documentada ${ }^{56}$. Podríamos poner más ejemplos como los de Bardají o Ruiz. Lo cierto es que tenía razón Bonifacio Palacios cuando insistía en que el uso que se hacía de la figura de los procuradores en cortes no era exclusivamente judicial, sino que realmente asumió un carácter político. Desde época de Jaime II era costumbre antigua el mandato pleno que tenían los procuradores municipales en cortes (plena potestas). Sin embargo, unas ordenanzas de la ciudad de Zaragoza otorgadas más de un siglo después por la reina María en 1442 fueron más allá. Por primera vez en la historia se aplicaba a los procuradores en cortes el mismo sistema de insaculación que los Trastámara venían introduciendo en la designación de la mayoría de los cargos municipales, limitando su número a cuatro. En verdad, había un primer procurador en dignidad que no se sorteaba y que se le asignaba por derecho al primer jurado o jurado en cap de la ciudad, pero los otros tres eran sorteados de la bolsa de insaculados para el cargo de jurados. Asistimos, en efecto, a un avance directo de la monarquía en su estrategia de control político de las ciudades, pues no sólo se manejaba así su designación afín al rey sino que además se lograba que acudiesen a cortes con plenos poderes, no para actuar sólo de abogados en proceso judicial, sino para tomar importantes decisiones políticas. Sin embargo, la existencia de consultas que hacían los procuradores a los jurados, según muestra la documentación zaragozana de la segunda mitad del siglo XV, confirma la obligación estricta que tenían bajo juramento de seguir las instrucciones que se les diesen antes o durante las sesiones parlamentarias, de hecho, en las actas municipales de 1469 se llega a decir que los sindicos de la ciutat no podien passar a los ditos actos sin consultar con el capitol e consello incluso en casos de urgencia ${ }^{57}$.

Desde hace tiempo contamos para Cataluña y Valencia con trabajos interesantes sobre el perfil social y la trayectoria política de los procuradores del brazo real a partir de documentos municipales ${ }^{58}$ y sobre la acción de las oligarquías urbanas en el escenario de las $\operatorname{cortes}^{59}$. La presencia de las ciudades en el caso de las cortes portuguesas o, en general, en las asambleas europeas de finales de la Edad Media ha sido tratada con amplitud y nos ofrece unos referentes interesantes para establecer análisis comparativos de mayor alcance ${ }^{60}$. Mientras tanto, para el reino de Aragón se han publicado

\footnotetext{
${ }^{56}$ Navarro 2009, pp. 170-173; Navarro 2017.

${ }^{57}$ Palacios 1985, p. 1261.

${ }^{58}$ Turull 2003; Martí 2004; Barrio 2009.

${ }^{59}$ Muñoz 2003, 2005.

${ }^{60}$ Sousa 1990; Hébert 2010, 2014.
} 
sendos libros de Luisa María Sánchez sobre las cortes de Alfonso V (14161458) y Juan II (1458-1479) -el segundo su tesis doctoral- que constituyen una investigación pionera en el tema que nos ocupa ${ }^{61}$. Esta autora planteó desde un principio la cuestión de la jerarquía interna que existía en el brazo de las universidades, insistiendo por ejemplo en que enviar procuradores a las cortes suponía un elevado gasto para las ciudades, villas y comunidades del reino, lo que limitaba también el número de procuradores que mandaban o a veces su ausencia ${ }^{62}$. Recordemos que en Castilla a partir de 1422 los gastos de los procuradores eran asumidos por la Hacienda Real, lo que en la práctica les convertía en oficiales reales ya que era la monarquía la que pagaba sus viajes y dietas ${ }^{63}$. Además, una vez admitidos los representantes de los brazos se procedía a la elección de los tratadores o negociadores que llevarían el peso de las deliberaciones, de ahí la escasa asistencia que registraban muchas asambleas al recaer el esfuerzo en pocas personas que trabajaban en la trastienda y preparaban los acuerdos que luego se ratificarían en las sesiones principales en presencia de todos y con solemnidad ${ }^{64}$. Así se comprende mejor la queja que presentaron ante el rey varias universidades en las Cortes de Alcañiz de 1436 contra los procuradores de Zaragoza respecto a los ocho diputados que negociaban los acuerdos y que la capital pretendía acaparar en beneficio propio:

E, senyor muy excellent, muestrase por obra, car los quatro diputados de la dita ciutat de Çaragoça, apoderándose de los otros quatro diputados, genyando e trayendo aquellos a su voluntat, hanse thomado pora si e pora ciudadanos de Çaragoça la mayor part de los officios pertenescientes en la present Cort al braço de las universidades ${ }^{65}$.

En las Cortes de Zaragoza de 1413-1414 aparece otra noticia interesante del 13 de marzo de 1414 que sigue mostrando la importancia que tenía mantener la jerarquía política de las universidades del reino. Se trata del conflicto que se había generado entre la ciudad de Teruel de una parte y su comunidad de aldeas de otra. Los procuradores de la comunidad se presentaban ante el rey como comunidat de las aldeas de la ciudat de Teruel et de la villa de Mosqueruela, denominación contra la que protestaban los de Teruel argumentando:

\footnotetext{
${ }^{61}$ Sánchez 1994, 2004.

${ }^{62}$ Sánchez 1994, p. 43.

${ }^{63}$ Carretero 1988.

${ }^{64}$ Sánchez 2004, p. 137.

${ }^{65}$ ACRA, tomo 9, vol. 2, p. 589.
} 
Et humilment supplicantes dizen que, atendientes et considerantes que yes question siquiere altercacion entre la universidat de la antedita ciudat de la una part et la comunidat de las aldeas et la villa de Mosqueruela de la otra, sobre esto que la part de la universidat de la antedita ciudat dize et affirma que a actos de cortes deven seyer constituidos procuradores o sindicos por las ditas ciudat et aldeas, includiendo soz las ditas aldeas Mosqueruela et no pas distintament asi como agora yes feyto por las ditas aldeas et Mosqueruela. Et que Mosqueruela yes et deve seyer havida por aldea et compresa soz las ditas aldeas et no deve seyer villa ni dever por tal seyer havida o reputada, los procuradores et comunidat de las ditas aldeas et villa de Mosqueruela de per si et distintament et menos de la ciudat ha podido et podia constituyr procuradores et sindicos pora los actos de cortes de Aragon, et que Mosqueruela yes et deve seyer havida villa et por villa et es de la dita comunidat et del cuerpo de aquella ${ }^{66}$.

Los de Teruel se olvidaban en su protesta de que la villa de Mosqueruela ya fue convocada en dos ocasiones a las Cortes de Aragón de 13651366 y 1367 respectivamente como se aprecia en la tabla 1. También la villa de Rubielos fue citada en 1365-1366 y era en teoría otra aldea de la comunidad de Teruel. El futuro daría la razón a los de Mosqueruela, que siguieron apareciendo adheridos a la comunidad turolense hasta que en las Cortes Generales de Monzón de 1510 volvieran a ser convocados como villa del brazo real por separado como en tiempos de Pedro IV. En la Tabla 2 puede comprobarse el orden de prelación que siguieron las 11 convocatorias de las cortes registradas en Aragón en el siglo que duró el gobierno de la dinastía Trastámara desde el advenimiento de Fernando I a la muerte de Fernando II (1412-1516). Por añadidura, la Tabla 3 establece una comparación directa con los datos del período anterior estudiado en las Tablas 1 y 2 (1336-1412), calculando una media ponderada global del número de puestos que ocuparon durante 1336-1514.

${ }^{66}$ ACRA, tomo 8, pp. 332-333. 
Tabla 2. Orden de convocatoria del brazo real en las Cortes de Aragón (1412-1514).

\begin{tabular}{|c|c|c|c|c|c|c|c|c|c|c|c|c|c|}
\hline & 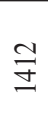 & 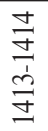 & 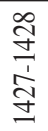 & Әे & 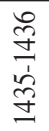 & $\frac{\underset{J}{J}}{\frac{J}{J}}$ & 导 & $\begin{array}{l}\stackrel{8}{7} \\
\frac{1}{b} \\
\dot{J} \\
\text { J }\end{array}$ & $\frac{\stackrel{ \pm}{J}}{\frac{1}{ \pm}}$ & $\stackrel{ }{2}$ & 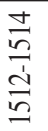 & $\begin{array}{l}\text { wa } \\
\dot{2} \\
\dot{z}\end{array}$ & 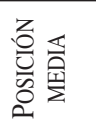 \\
\hline Aínsa & 27 & 22 & 20 & 19 & 13 & 12 & 12 & 17 & 18 & 19 & 20 & 11 & 18,09 \\
\hline Alagón & & & 15 & 18 & 20 & 18 & 18 & 22 & 23 & 23 & 24 & 9 & 20,11 \\
\hline Albarracín & 8 & 6 & 9 & 7 & 7 & 6 & 6 & 8 & 9 & 8 & 8 & 11 & 8,18 \\
\hline $\begin{array}{l}\text { Albarracín } \\
\text { (com. aldeas) }\end{array}$ & & & & & & & & & & 15 & 16 & 2 & 15,50 \\
\hline Alcañiz & 13 & 7 & 10 & 15 & 10 & 9 & 9 & 9 & 10 & 11 & 11 & 11 & 10,36 \\
\hline Almudévar & 21 & 26 & 13 & 14 & & & & & & 30 & 31 & 6 & 19,16 \\
\hline Alquézar & & & & & & & & 25 & 26 & 26 & 27 & 4 & 26,00 \\
\hline Barbastro & 9 & 8 & 8 & 8 & 9 & 8 & 8 & 7 & 8 & 6 & 6 & 11 & 7,72 \\
\hline Bolea & & & & & & & & & & 32 & & 1 & 32,00 \\
\hline Borja & & & & & & & & & & 10 & 10 & 2 & 10,00 \\
\hline Calatayud & 6 & 2 & 5 & 4 & 4 & 3 & 3 & 4 & 5 & 5 & 5 & 11 & 4,18 \\
\hline $\begin{array}{l}\text { Calatayud } \\
\text { (com. aldeas) }\end{array}$ & 11 & 16 & 25 & 26 & 24 & 22 & 22 & 12 & 13 & 14 & 14 & 11 & 18,09 \\
\hline Canfranc & & & & & & & & & & 33 & & 1 & 33,00 \\
\hline Daroca & 5 & 3 & 6 & 6 & 5 & 4 & 4 & 6 & 7 & 7 & 7 & 11 & 5,45 \\
\hline $\begin{array}{l}\text { Daroca } \\
\text { (com. aldeas) }\end{array}$ & 10 & 15 & 26 & 13 & 25 & 23 & 23 & 13 & 14 & & 15 & 10 & 17,70 \\
\hline Ejea & 16 & 21 & 22 & 12 & 16 & 15 & 15 & 10 & 11 & 12 & 12 & 11 & 14,72 \\
\hline Fraga & 26 & 11 & 21 & 17 & 22 & 20 & 20 & 16 & 17 & 18 & 19 & 11 & 18,81 \\
\hline Huesca & 3 & 9 & 3 & 2 & 2 & 2 & 2 & & 2 & 2 & 2 & 10 & 2,90 \\
\hline Jaca & 4 & 13 & 2 & 5 & 8 & 7 & 7 & 2 & 3 & 4 & 4 & 11 & 5,36 \\
\hline Loarre & & & & & & & & & & 34 & & 1 & 34,00 \\
\hline Magallón & & & & & & & & & & 29 & 30 & 2 & 29,50 \\
\hline Montalbán & 14 & 25 & 11 & 16 & 11 & 10 & 10 & 14 & 15 & 16 & 17 & 11 & 14,45 \\
\hline Monzón & 24 & & & & 12 & 11 & 11 & 15 & 16 & 17 & 18 & 8 & 15,50 \\
\hline Mosqueruela & & & & & & & & & & 31 & & 1 & 31,00 \\
\hline Sádaba & 17 & 19 & 19 & 11 & 19 & 17 & 17 & 23 & 24 & 24 & 25 & 11 & 19,54 \\
\hline $\begin{array}{l}\text { San Esteban } \\
\text { de Litera }\end{array}$ & 22 & 10 & 23 & 25 & 23 & 21 & 21 & 21 & 22 & 27 & 28 & 11 & 22,09 \\
\hline Sariñena & 25 & 18 & 18 & 22 & 17 & & & 19 & 20 & 21 & 22 & 9 & 20,22 \\
\hline Sos & 19 & 20 & 17 & 20 & 18 & 16 & 16 & & & 28 & 29 & 9 & 20,33 \\
\hline $\begin{array}{l}\text { Tamarite } \\
\text { de Litera }\end{array}$ & 23 & 12 & 16 & 21 & 14 & 13 & 13 & 20 & 21 & 22 & 23 & 11 & 18,00 \\
\hline Tarazona & 2 & 4 & 4 & 3 & 3 & & & 5 & 6 & 3 & 3 & 9 & 3,66 \\
\hline Tauste & 15 & 24 & 14 & 9 & 15 & 14 & 14 & 24 & 25 & 25 & 26 & 11 & 18,63 \\
\hline Teruel & 7 & 5 & 7 & 10 & 6 & 5 & 5 & 3 & 4 & 9 & 9 & 11 & 6,36 \\
\hline $\begin{array}{l}\text { Teruel } \\
\text { (com. aldeas) }\end{array}$ & 12 & 23 & 24 & 24 & 26 & 24 & 24 & 11 & 12 & 13 & 13 & 11 & 18,72 \\
\hline Uncastillo & 18 & 14 & 12 & 23 & 21 & 19 & 19 & 18 & 19 & 20 & 21 & 11 & 18,54 \\
\hline Zaragoza & 1 & 1 & 1 & 1 & 1 & 1 & 1 & 1 & 1 & 1 & 1 & 11 & 1,00 \\
\hline Zuera & 20 & 17 & & & & & & & & & & 2 & 18,50 \\
\hline TOTAL & 27 & 26 & 26 & 26 & 26 & 24 & 24 & 25 & 26 & 34 & 31 & & 26,81 \\
\hline
\end{tabular}


Tabla 3. Posición media y número de veces que fueron convocados en las Cortes de Aragón (1336-1514).

\begin{tabular}{|l|r|r|r|}
\hline & $1336-1514$ & $1336-1412$ & $1412-1514$ \\
\hline Zaragoza & $1,00(31)$ & $1,00(20)$ & $1,00(11)$ \\
\hline Huesca & $4,00(30)$ & $4,55(20)$ & $2,90(10)$ \\
\hline Tarazona & $4,26(26)$ & $4,82(17)$ & $3,66(09)$ \\
\hline Jaca & $5,09(31)$ & $4,95(20)$ & $5,36(11)$ \\
\hline Calatayud & $5,99(28)$ & $7,17(17)$ & $4,18(11)$ \\
\hline Barbastro & $6,38(31)$ & $5,65(20)$ & $7,72(11)$ \\
\hline Daroca & $6,61(31)$ & $7,25(20)$ & $5,45(11)$ \\
\hline Albarracín & $6,63(22)$ & $5,09(11)$ & $8,18(11)$ \\
\hline Teruel & $6,71(28)$ & $6,94(17)$ & $6,36(11)$ \\
\hline Alcañiz & $13,16(31)$ & $14,70(20)$ & $10,36(11)$ \\
\hline Ejea & $14,41(31)$ & $14,25(20)$ & $14,72(11)$ \\
\hline Pertusa & $14,50(02)$ & $14,50(02)$ & \\
\hline Albarracín (com. aldeas) & $15,00(03)$ & $14,00(01)$ & $15,50(02)$ \\
\hline Rubielos & $15,00(01)$ & $15,00(01)$ & \\
\hline Montalbán & $15,03(31)$ & $15,35(20)$ & $14,45(11)$ \\
\hline Uncastillo & $15,80(31)$ & $14,30(20)$ & $18,54(11)$ \\
\hline Monzón & $16,00(24)$ & $16,25(16)$ & $15,50(08)$ \\
\hline Borja & $16,00(10)$ & $17,50(08)$ & $10,00(02)$ \\
\hline Hoz & $16,00(01)$ & $16,00(01)$ & \\
\hline Almudévar & $16,07(24)$ & $15,05(18)$ & $19,16(06)$ \\
\hline Aínsa & $16,09(30)$ & $14,94(19)$ & $18,09(11)$ \\
\hline Tauste & $16,31(28)$ & $14,82(17)$ & $18,63(11)$ \\
\hline Huesa & $34,00(00)$ & & \\
\hline Sariñena & $16,50(02)$ & $16,50(02)$ & \\
\hline Calatayud (com. aldeas) & $17,29(20)$ & $14,90(11)$ & $20,22(09)$ \\
\hline Daroca (com. aldeas) & $17,76(21)$ & $17,40(10)$ & $18,09(11)$ \\
\hline Tamarite de Litera & $17,90(20)$ & $18,10(10)$ & $17,70(10)$ \\
\hline Sádaba & $18,21(23)$ & $18,41(12)$ & $18,00(11)$ \\
\hline Zuera & $18,51(27)$ & $17,81(16)$ & $19,54(11)$ \\
\hline Sos & $18,78(14)$ & $18,83(12)$ & $18,50(02)$ \\
\hline Ariza & $19,11(25)$ & $18,43(16)$ & $20,33(09)$ \\
\hline San Esteban de Litera & $19,55(09)$ & $19,55(09)$ & \\
\hline Teruel (com. aldeas) & $19,58(17)$ & $15,00(06)$ & $22,09(11)$ \\
\hline Alagón & $19,74(20)$ & $21,00(09)$ & $18,72(11)$ \\
\hline Fraga & $19,92(26)$ & $19,82(17)$ & $20,11(09)$ \\
\hline Mosqueruela & $19,99(14)$ & $24,33(03)$ & $18,81(11)$ \\
\hline Épila & $20,33(03)$ & $15,00(02)$ & $31,00(01)$ \\
\hline Ricla & $21,00(04)$ & $21,00(04)$ & \\
\hline Magallón & $21,00(02)$ & $21,00(02)$ & \\
\hline Cetina & $22,00(08)$ & $19,50(06)$ & $29,50(02)$ \\
\hline Alquézar & $24,00(0)$ & $24,50(04)$ & \\
\hline Horta & $26,00(01)$ & $26,00(04)$ \\
\hline Aranda & $26,00(01)$ & \\
\hline Bolea & & & \\
\hline Canfranc & $32,00(01)$ & \\
\hline Loarre & & & \\
\hline
\end{tabular}


Las Cortes de Maella de 1423 y las de Alcañiz-Zaragoza de 14411442 ofrecen los últimos ejemplos conocidos sobre la Forma del asentar las Cortes que nos recuerdan las disposiciones precedentes de las Cortes Generales de 1375-1376, 1383-1384 y 1388-138967. El orden de asiento del brazo real repetido en ambas cortes se asigna sólo a 21 universidades de las 36 que fueron convocadas durante 1412-1514 (véase Tabla 2) y de las 46 que lo fueron en total durante todo el período 1336-1514 (véase Tabla 3):

\begin{tabular}{|l|l|l|}
\hline Huesca & Zaragoza & Tarazona \\
\hline Albarracín & Jaca & Barbastro \\
\hline Daroca & Calatayud & Teruel \\
\hline Alcañiz & Aldeas de Calatayud & Aldeas de Daroca \\
\hline Aldeas de Teruel & Montalbán & Fraga \\
\hline Tamarite de Litera & Sos & Alagón \\
\hline Almudévar & Sariñena & Tauste \\
\hline
\end{tabular}

Las Cortes de Aragón en época Trastámara tuvieron un desarrollo menos intenso que el conocido durante el siglo precedente con Pedro IV. La reina María, esposa de Alfonso V, o el rey Juan de Navarra, hermano del monarca y futuro sucesor como Juan II de Aragón, actuando como lugartenientes sólo celebraron nueve cortes aragonesas y una general de la Corona. Y las preocupaciones giraban más en torno a las relaciones con Castilla que a los problemas internos de Aragón. Cuando Juan se convirtió en Juan II también reunió sólo tres veces a las cortes aragonesas y una general de la Corona, la mayoría de ellas breves y centradas en sus problemas con Cataluña. Las asambleas que más años duraron tuvieron una decena de sesiones plenarias como mucho. Con Fernando el Católico hubo unas generales al comienzo del reinado y dos consecutivas en los últimos años. Respecto a las Cortes de Aragón se celebraron dos en Zaragoza y otras dos en Tarazona. Pero igual que sus predecesores, el último monarca de la dinastía Trastámara ya no necesitaba apoyarse en los brazos de las cortes para llevar a término su ambiciosa política internacional. Así, las propias cortes generales dejaron de ser reuniones conjuntas como sucedía antaño para pasar a ser en realidad tres asambleas distintas congregadas en un mismo lugar ${ }^{68}$.

${ }^{67}$ ACRA, tomo 9, vol. 1, pp. 1-2; tomo 10, vol. 1, p. 11.

${ }^{68}$ Navarro 2015b. 


\section{CONCLUSIONES}

Por primera vez aquí se ha procesado y comparado toda la información existente en las actas de las cortes medievales de Aragón publicadas hasta la fecha acerca del orden de convocatoria y asiento de las ciudades, villas y comunidades de aldeas que formaban el brazo real de las universidades. Un repaso exhaustivo de todas las noticias que pudieran aludir a la conflictividad y reciprocidad existentes entre las poblaciones integrantes del brazo nos ha proporcionado datos interesantes acerca de cómo estas aceptaban la jerarquía política que los reyes establecían sobre todas. Visto lo visto, no creemos estar en el reino de Aragón ante una jerarquía sin sistema como define Andrea Zorzi el mundo urbano de la Toscana presidido por Florencia en los siglos XV-XVI. El brazo real de las universidades en Aragón era concebido como un verdadero "sistema urbano" por la monarquía pretendiendo englobar a los principales lugares del reino con epicentro en la capital, Zaragoza. Esa concepción política fue aceptada por los representantes electos de las poblaciones y comunidades que participaban en cortes. Es decir, los reyes no sólo ejercieron su soberanía mediante el poder de convocar las asambleas, también lo hicieron ordenándolas en su interior con una clasificación política que era aceptada por los procuradores del brazo real cuyo poder emanaba y procedía de un conjunto de varias decenas de concejos y comunidades que consensuaba sus acuerdos entre sí y respecto a los otros tres brazos de las cortes aragonesas, pero que, además, se influían mutuamente en otros muchos aspectos económicos, sociales, institucionales y culturales como la defensa de los ideales de justicia, derecho y representación. Las propias comunidades de aldeas eran pequeños subsistemas de centros rurales que se solapaban con el sistema más amplio de coaliciones entre concejos vecinos o no tan vecinos. A veces algunas poblaciones hasta consideraban oportuno acudir juntas a las cortes para protegerse de la violencia en los caminos, como Huesca, Jaca y Barbastro en tiempos del Parlamento del Interregno. En suma, los reyes diseñaron a la medida de su reino aragonés un sistema urbano jerarquizado coherente con las bases demográficas y materiales del territorio que abarcaba el estado feudal. Algo parecido sucedió también en Cataluña y Valencia con el protagonismo de sus respectivas ciudades capitales sobre los sistemas urbanos que presidían ambos territorios, como si se tratara de estrellas alrededor de las cuales giraban constelaciones de planetas. 


\section{BIBLIOGRAFÍA CITADA}

Asenjo, María; Crouzet-Pavan, Elisabeth (coords.) (2015), Competencias políticas e institucionales de las ciudades de Europa y América (14001561). Integración y concurrencia, Madrid, 1-2 de octubre de 2015, Madrid, Casa de Velázquez - Universidad Complutense.

Barrio, Juan Antonio (2009), Los procuradores del brazo real en las cortes medievales del reino de Valencia, "Aragón en la Edad Media" 21, pp. 59-98.

Bourdieu, Pierre (2014), Sobre el Estado. Cursos en el Collège de France (1989-1992), Barcelona, Anagrama.

Carretero, Juan Manuel (1988), Cortes, Monarquía, Ciudades. Las Cortes de Castilla a comienzos de la época moderna (1476-1515), Madrid, Siglo XXI.

Genet, Jean-Philippe (dir.) (2017), Consensus et représentation, París, Publications de la Sorbonne.

González, Luis (2007), España y las Españas, Madrid, Alianza.

Hébert, Michel (2010), L'ordre des discours: les conflits de préséance entre villes dans les assemblées parlementaires de la fin du Moyen Âge, "Académie des Inscriptions et Belles-Lettres. Comptes rendus des séances de l'année 2009”, pp. 125-152.

Hébert, Michel (2014), Parlementer. Assemblées représentatives et échanges politique en Europe occidentale à la fin du Moyen Âge, París, Boccard.

Iradiel, Paulino (1997), Señoríos jurisdiccionales y poderes públicos a finales de la Edad Media en Poderes públicos en la Europa medieval: principados, reinos y coronas. $23^{a}$ Semana de Estudios Medievales de Estella (22-26 de julio de 1996), Pamplona, Gobierno de Navarra, pp. 69-116.

Iradiel, Paulino (1999): Ciudades, comercio y economía artesana en La historia medieval en España. Un balance historiográfico (1968-1998), $25^{a}$ Semana de Estudios Medievales de Estella, Pamplona, Gobierno de Navarra, pp. 603-658.

Iranzo, María Teresa, (ed.) (2007), Cortes del reinado de Alfonso V/1, Zaragoza, Gobierno de Aragón (ACRA; 9-2)

Laliena, Carlos (ed.) (2008), Cortes del reinado de Pedro IV/2, Zaragoza, Gobierno de Aragón (ACRA; 3).

Laliena, Carlos (2015), Saragossa, capital medieval del regne d'Aragó, "Afers" 80/81, pp. 83-111.

Laliena, Carlos, Iranzo, María Teresa (eds.) (2016), Cortes del reinado de Alfonso V/2, Zaragoza, Gobierno de Aragón (ACRA; 10-3). 
Martí, Esther (2004), El síndic municipal a Corts a la Corona d'Aragó, durant el regnat d'Alfons el Magnànim: el cas de Lleida, "Anuario de Estudios Medievales" 34/2, pp. 831-873.

Monterde, Cristina (ed.) (2011), Cortes del reinado de Fernando II/4, Zaragoza, Gobierno de Aragón (ACRA; 16-2.)

Muñoz, María Rosa (2003), Las ciudades y las Cortes: la presencia de las oligarquías urbanas en las Cortes de Alfonso el Magnánimo en Actes del XVII Congrès d'Història de la Corona de Aragó, BarcelonaLleida 2000, vol. 3, pp. 673-693.

Muñoz, María Rosa (2005), La ciudad de Valencia en las Cortes: posiciones y resultados (1400-1418) en Actes del 53è Congrés de la Comissió Internacional per a l'Estudi de la Història de les Institucions Representatives i Parlamentàries, Barcelona, Parlament de Catalunya i Museu d'Història de Catalunya, vol. 1, pp. 223-256.

Navarro, Germán (2004), Los notarios y el Estado aragonés (siglos XIV-XV) en Barrio, Juan Antonio (ed.), Los cimientos del Estado en la Edad Media, Alicante, Editorial Marfil, pp. 39-63.

Navarro, Germán (ed.) (2008), Cortes del reinado de Martín I, Zaragoza, Gobierno de Aragón, (ACRA; 6-2)

Navarro, Germán (ed.) (2009), Cortes del reinado de Fernando I, Zaragoza, Gobierno de Aragón (ACRA; 8)

Navarro, Germán (2009), Consejeros influyentes y personas de confianza en el entorno cortesano de los reyes de Aragón (siglos XIII-XV) en Sesma, José Ángel (coord.), La Corona de Aragón en el centro de su historia, 1208-1258. La monarquía aragonesa y los reinos de la Corona. Zaragoza, Gobierno de Aragón, pp. 129-179.

Navarro, Germán (2010), Ciudades y villas del reino de Aragón en el siglo XV. Proyección institucional e ideología burguesa, "Anales de la Universidad de Alicante. Historia Medieval" 16, pp. 195-221.

Navarro, Germán (2015a), La Representación Aragonesa en Perpiñán. Del Concilio de 1408-1409 a la cumbre europea de 1415 en Colloque International Perpignan 1415: Un sommet européen à l'époque des conciles (Université de Perpignan, 24-25 septiembre 2015), Münster - Berlin, Geschitche und Kultur der Iberischen Welt (en prensa).

Navarro, Germán (2015b), Las cortes del reino de Aragón en la Edad Media (1283-1516), "e-Humanista. Journal of Iberian Studies," 7, pp. 231-244.

Navarro, Germán (2017), La historia de Juan Ruiz, merino de Zaragoza y consejero del rey Alfonso V de Aragón en Lafuente, Mario; Villanueva, Concepción (coords.), Los agentes del Estado. Poderes públicos y dominación social en Aragón (siglos XIV-XVI), Universidad de Zaragoza, 20-21 junio 2017 (en prensa). 
Nieto, José Manuel (2007), Medievo constitucional. Historia y mito político en los orígenes de la España contemporánea (ca. 1750-1814), Madrid, Akal.

Palacios, Bonifacio (1985), La representación municipal en Cortes. Estudio de la figura del Procurador de Zaragoza a mediados del siglo XV en La ciudad hispánica durante los siglos XIII al XVI, Madrid, Universidad Complutense, tomo 2, pp. 1241-1267.

Reynolds, Susan (1997), Kingdoms and Communities in Western Europe, 900 1300, Oxford, Clarendon Press ( $2^{\mathrm{a}}$ ed.).

Sánchez, Luisa María (1994), Cortes, monarquía y ciudades en Aragón durante el reinado de Alfonso el Magnánimo (1416-1458), Zaragoza, Institución Fernando el Católico.

Sánchez, Luisa María (2004), Las Cortes de la Corona de Aragón durante el reinado de Juan II (1458-1479): monarquía, ciudades y relaciones entre el poder y los súbditos, Zaragoza, Institución Fernando el Católico.

Sesma, José Ángel (ed.) (2006), Cortes del reinado de Pedro IV, Zaragoza, Gobierno de Aragón (ACRA; 4).

Sesma, José Ángel (ed.) (2009), Cortes del reinado de Pedro IV/4 y Juan I, Zaragoza, Gobierno de Aragón, (ACRA; 5).

Sesma, José Ângel (ed.) (2011), Parlamentos del Interregno, Zaragoza, Gobierno de Aragón (ACRA; 7-2)

Sesma, José Ángel (2011), El Interregno (1410-1412). Concordia y compromiso político en la Corona de Aragón, Zaragoza, Institución Fernando el Católico.

Sesma, José Ángel; Laliena, Carlos; Monterde, Cristina (2012), En el Sexto Centenario de la Concordia de Alcañiz y del Compromiso de Caspe, Zaragoza, Gobierno de Aragón.

Sesma, José Ângel; Laliena, Carlos (2012), Las elites políticas de Aragón durante el Interregno y el Compromiso de Caspe en Sesma, José Ángel (coord.), La Corona de Aragón en el centro de su historia, 12081458. El Interregno y el Compromiso de Caspe, Zaragoza, Gobierno de Aragón, pp. 165-232.

Sesma, José Ángel, Lafuente, Mario (eds.) (2013) Cortes y parlamentos del reinado de Pedro IV/1, Zaragoza, Gobierno de Aragón (ACRA; 2).

Sousa, Armindo de (1990), As Cortes Medievais Portuguesas (1385-1490), 2 vols., Porto, Instituto Nacional de Investigação Científica.

Tomás, Guillermo (2013), Berenguer de Bardaji: el ascenso social de un linaje montañés en Falcón, María Isabel (ed.), El Compromiso de Caspe (1412), cambios dinásticos y constitucionalismo en la Corona de Aragón, Zaragoza, Gobierno de Aragón, pp. 847-854. 
Tomás, Guillermo (ed.) (2013), Cortes de Alfonso V/3, Zaragoza, Gobierno de Aragón (ACRA; 11)

Turull, Max (2003), Síndicos a Cortes. Perfil social, político e institucional de los representantes ciudadanos a Cortes y parlamentos de Cataluña (1333-1393) en Actes del XVII Congrés d'Història de la Corona d'Aragó, Barcelona, Publicacions de la Universitat de Barcelona, vol. 3, pp. 989-1012.

Watts, John (2009), The Making of Polities. Europe, 1300, Cambridge, Cambridge University Press.

Wickham, Chris (2008), Una historia nueva de la Alta Edad Media. Europa y el mundo mediterráneo, 400-800, Barcelona, Crítica.

Wickham, Chris (2009), Memorias del subdesarrollo: ¿Qué ha hecho el marxismo por la historia medieval, y qué puede hacer aún?, "Anales de Historia Antigua, Medieval y Moderna” 41, pp. 85-100.

Wickham, Chris (2017), Europa en la Edad Media. Una nueva interpretación, Barcelona, Crítica.

Fecha de recepción del artículo: octubre 2017

Fecha de aceptación y versión final: febrero 2018 